Article

\title{
Towards Eco-Flowable Concrete Production
}

\author{
Maria Rashidi ${ }^{1, *}$, Alireza Joshaghani ${ }^{2, *}$ and Maryam Ghodrat ${ }^{1}$ \\ 1 Centre for Infrastructure Engineering, Western Sydney University, Penrith, NSW 2751, Australia; \\ m.ghodrat@westernsydney.edu.au \\ 2 Zachry Department of Civil Engineering, Texas A\&M University, College Station, TX 77840, USA \\ * Correspondence: m.rashidi@westernsydney.edu.au (M.R.); joshaghani@tamu.edu (A.J.)
}

Received: 20 December 2019; Accepted: 3 February 2020; Published: 7 February 2020

\begin{abstract}
Environmental concerns have increased due to the amount of unused/expired plastic medical waste generated in hospitals, laboratories, and other healthcare facilities, in addition to the fact that disposing of such wastes with extremely low degradation levels causes them to remain in the environment for extended periods of time. These issues have led researchers to develop more environmentally friendly alternatives for disposing of plastic medical waste in Australia. This study is an attempt to assess the impacts of using expired plastic syringes as fine aggregate on fresh and hardened characteristics of flowable concrete, which might provide a solution to environmental concerns. Six mixtures of flowable concrete with water-to-cement ratios of 0.38 were studied. It was found that using recycled aggregate in up to $20 \%$ can improve the workability and increase the V-funnel values of flowable concrete mixtures. However, using waste aggregates in more than $30 \%$ caused an inapt flowability. Adding waste aggregate at the 30\%-50\% replacement level led to a decrease in the L-box ratio. To verify the utility and the efficacy of this experiment, the connections between different rheological test measurements were also compared by implementing the Pearson correlation function. The mechanical properties of the mixes containing recycled aggregates were decreased at the age of seven days; however, at later ages, waste aggregates increased the strength at the $10 \%-30 \%$ replacement levels.
\end{abstract}

Keywords: flowable concrete; expired plastic syringes; rheological properties; mechanical behavior

\section{Introduction}

Numerous plastic products are being consumed with the development of society. However, large amounts of plastic waste pose a threat to the environment due to the very low biodegradability of plastic. It is necessary to develop a rational approach to waste disposal which addresses both the economy and environmental protection [1]. The use of recycled plastic aggregates in concrete can reduce the cost, alleviate an environmental problem, and save energy. In the last few decades, the recycling of waste materials has been a serious concern due to the boundaries of landfill spaces and the growing expenses. Based on a national report in 2016, Australia produced 59,000 tons of medical waste each year (Australia's report to the Basel Convention) [2]; disposable syringes made up a large proportion of the overall medical waste production. Plastic syringes contain a high percentage of plastic (about $90 \%$ ), which means that they have high potential to be recycled. Currently, the main method instated by hospitals for expired plastic syringes is to pass expired plastic syringes through collection agencies, who dump them into landfills. However, recently, there have been significant increases in landfill levees, raising the price of non-recycled waste such as waste syringes.

There are opportunities for using these wastes in other fields, particularly in the construction industry. The field of research on the assessment of the application of plastic waste in concrete mixtures has gained popularity in the last few decades. The use of waste plastic bottles [3], waste PVC 
pipe [4], and shredded and recycled plastic waste [5-9] has been investigated by various researchers. Numerous studies have also been carried out on the usage of scrap rubber in both mortar and concrete $[10,11]$. In fact, using recycled plastic can improve concrete durability when used as fiber. It has also been found that using waste plastic as fiber in concrete leads to a growth in flexural and splitting-tensile strength [12,13]; at the same time, shrinkage and permeability decreased [14]. Other groups of researchers reported that increasing the amount of plastic waste causes a reduction in splitting-tensile, flexural, and compressive strength $[15,16]$. The main reason for this behavior is the incompatibility between the cement paste and plastic particles [15]. In addition, some researchers found that the shape of the plastic particles is a definitive parameter, in that sharp edges lead to a reduction in slump value [17]. On the other hand, adding plastic particles with a spherical shape enhances fluid ability.

It is observed that previous studies are mainly aimed at the properties of plastic waste as an aggregate substitution in ordinary concrete. Work related to self-compacting concrete containing plastic particles is relatively scarce. Just a few studies are found about the effect of plastic waste on the properties of self-compacting concrete. Overall, based on the detailed survey in the literature, it has been perceived that most of the research carried out so far is on assessing the implementation of plastic waste as a substitution for aggregate in ordinary concrete. There are relatively few studies found on fresh properties of flowable concrete with plastic particles; however, just a few studies have been done on the impact of plastic medical waste on properties of flowable concrete. This oversight is particularly unfortunate considering that flowable concrete has been increasingly used in stay-in-place formwork structures, concrete-filled steel columns, and prefabricated PVC walls and columns because of their light weight, construction simplicity, and their lower noise levels [18,19].

This study focused on integrating the expired plastic syringes into the matrix of flowable concrete mortar as a replacement for fine aggregate. The objective is to reduce the environmental footprint of expired plastic syringes and to avoid sending them into landfills. Recycled medical waste aggregate is produced from expired plastic syringes. This experimental study was done to evaluate the fresh and hardened properties of the flowable concrete with different proportions of fine aggregate substituted by shredded expired plastic syringes.

\section{Experimental Study}

The experimental study aims to promote the use of sustainable forms of flowable concrete by incorporating recycled aggregates from shredded expired plastic syringes and to develop information on their fresh and hardened mechanical properties.

\subsection{Materials and Mix Properties}

Cement type I with a fineness of $2850 \mathrm{~cm}^{2} / \mathrm{gr}$ and a specific gravity of 3.16 was added to the mixture as the main cementitious material. The chemical composition of the cement is shown in Table 1. The natural coarse aggregate was limestone gravel with a nominal maximum size of $12.5 \mathrm{~mm}$. The specific gravity and water absorption of the coarse aggregate in flowable concrete were 2.82 and $1.95 \%$, respectively. As a fine aggregate, concrete aggregate with a maximum size of $4.75 \mathrm{~mm}$ was added to the mixture. In addition, the fine aggregate had a specific gravity and water absorption of 2.67 and $2.51 \%$, respectively. The physical properties of the aggregates are shown in Table 2 . The natural aggregate gradation is shown in Figure 1 with black lines. Moreover, the recycled coarse and fine aggregates are shown in Figure 1 with solid and dashed red lines, respectively. a High-Range Water-Reducing Admixture (HRWRA) with a polycarboxylic-ether base and a specific gravity of 1.09 was used in this study. The HRWRA was used in flowable concrete mixes to reach the flowability target, i.e., the initial slump flow of $650 \pm 25 \mathrm{~mm}$. 
Table 1. Chemical and physical properties of Type I cement.

\begin{tabular}{cc}
\hline Chemical Properties & (wt. \%) \\
\hline $\mathrm{SiO}_{2}$ & 20.03 \\
$\mathrm{Al}_{2} \mathrm{O}_{3}$ & 5.53 \\
$\mathrm{Fe}_{2} \mathrm{O}_{3}$ & 3.63 \\
$\mathrm{CaO}$ & 62.25 \\
$\mathrm{MgO}$ & 3.42 \\
$\mathrm{SO}$ & 2.23 \\
$\mathrm{~K}_{2} \mathrm{O}$ & 0.73 \\
$\mathrm{Na}_{2} \mathrm{O}$ & 0.3 \\
Specific gravity $\left(\mathrm{kg} / \mathrm{m}^{3}\right)$ & 3150 \\
Specific surface area $\left(\mathrm{m}^{2} / \mathrm{kg}\right)$ & 290 \\
\hline
\end{tabular}

Table 2. Physical properties of aggregates.

\begin{tabular}{cccc}
\hline Properties & Coarse Aggregate & Fine Aggregate & Plastic Waste \\
\hline Specific Gravity & 2.82 & 2.67 & 0.97 \\
Water Absorption (\%) & 1.95 & 2.51 & 0.1 \\
Maximum Size (mm) & 12.5 & 4.75 & 4.75 \\
\hline
\end{tabular}

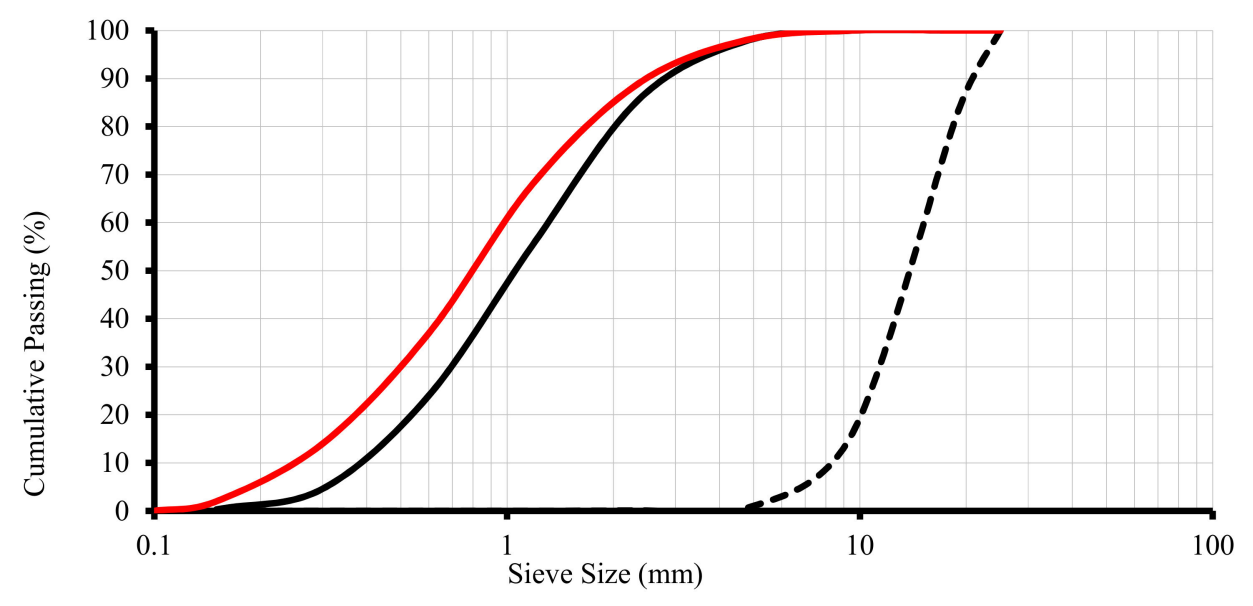

- - - Natural Coarse Aggregate $\longrightarrow$ Natural Fine Aggregate $\quad$ Recycled Fine Aggregate

Figure 1. Sieve analysis of coarse and fine aggregates for both natural and recycled aggregates.

\subsection{Preparation of Expired Plastic Syringe Aggregate}

The flowable concrete mixes of the experimental program were produced using natural aggregates and aggregates from shredded expired plastic syringes. The recyclability of the syringes' bodies and needle attachments were considered initially; this provided a relatively wide scope of materials, e.g., plastic, metal, and rubber. Plastic syringes (50 and $10 \mathrm{~mL}$ used in this study) have a high plastic content (around 90\%). About 400 expired 50 and $10 \mathrm{~mL}$ plastic syringes with different brands and manufacturers were collected from hospitals, laboratories, and dental clinics all around the greater Sydney region. The unused syringes were then shredded by a $1.5 \mathrm{~kW}$ jaw crusher, as shown in Figure 2a; the steel needle parts were then removed by a 2 ton Beaver Permanent Magnet Lifter (Figure 2b). 


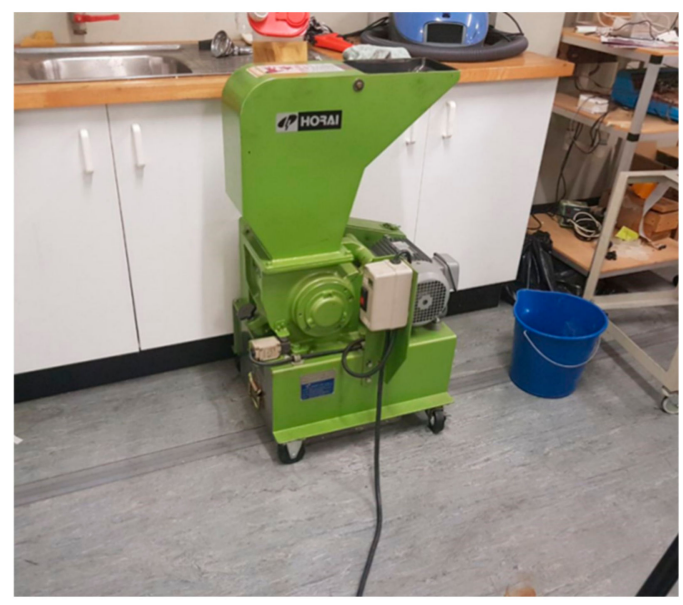

(a) The jaw crusher

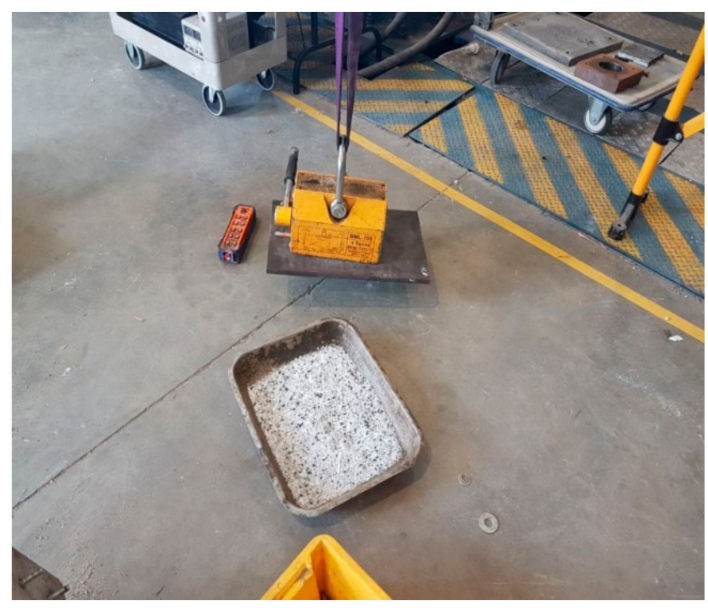

(b) The magnet lifter for removing steel needle parts

Figure 2. Waste plastic sample preparation.

Figure 3 represents the plastic types that exist in expired plastic syringes: Rubber, white, green, and crystal plastic. As can be seen from Figure 3, the crushed particles of the rubber plunger are bigger in size when compared with other plastic particles. The microstructural properties of the four plastic types were examined in order to understand the elements that exist in each type.

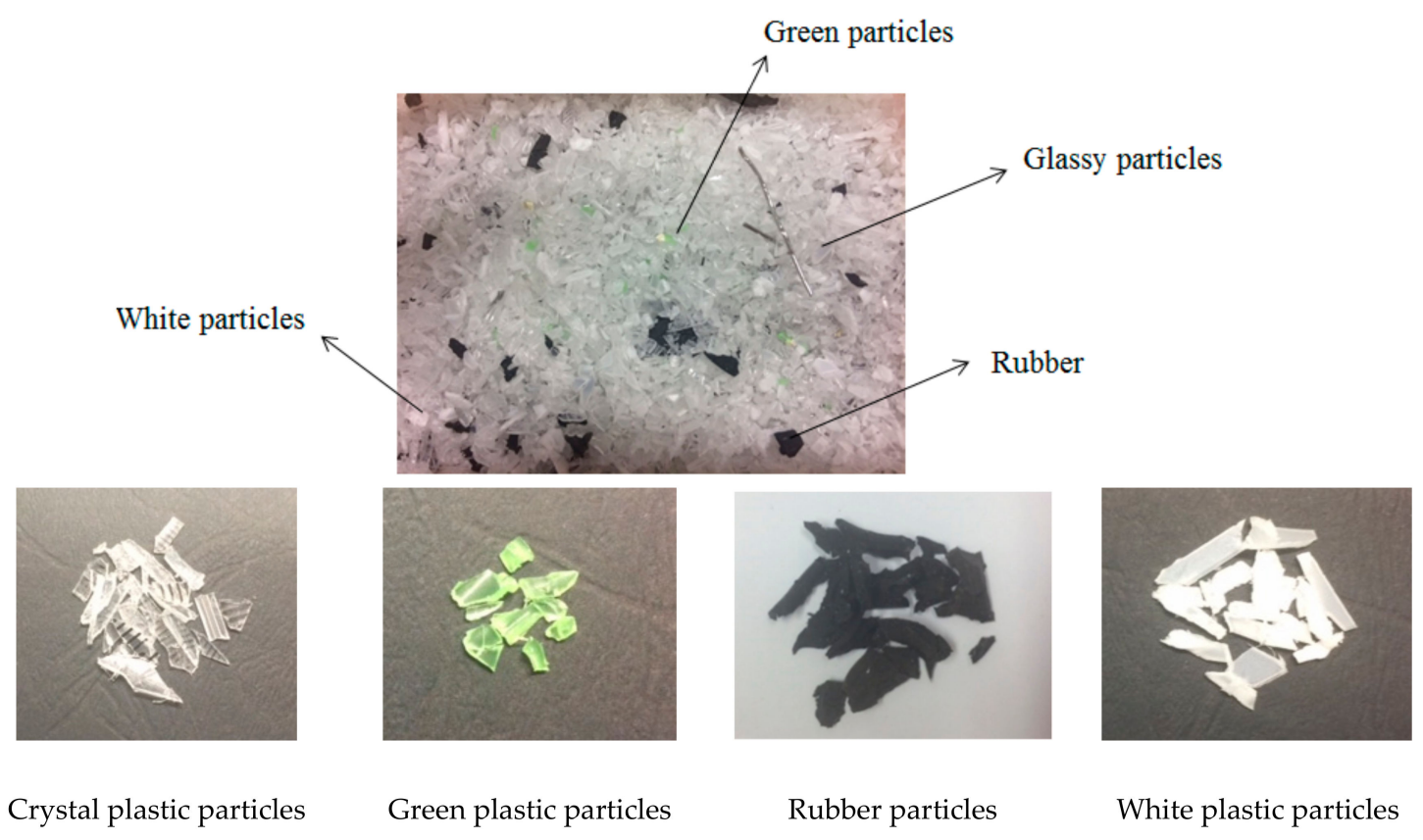

Figure 3. Types of plastic in the expired plastic syringes collected from hospitals and vet clinics.

\subsection{Microstructural Properties of Waste Plastic Syringe Composites}

Scanning electron microscopy (SEM) and energy-dispersive spectroscopy (EDS) tests of ground expired plastic syringes were carried out to analyze the elements existing in these wastes. Four types of plastic particles, including rubber, crystal plastic, green plastic, and white plastic were visually detected and examined. The elemental analyses of these four plastic particles are reported in Figure 4. Samples were X-ray mapped using a JEOL JXA-8600 super probe SEM with an "AMPTEK" EDS silicon drift detector [20]. SEM allows greater magnification, resolution, and depth-of-field than those of an optical microscope. X-ray microanalysis was used to identify, locate, and quantify the elements that compose a specimen, as shown in Figure 4. The results showed the elemental differences between the 
different plastic particles in expired syringes. As can be seen from Figure 4, carbon is the dominant element in all plastic particle types detected in expired syringes except rubber particles, in which $\mathrm{SiO}_{2}$ plays a governing role, followed by $\mathrm{CaO}$ and $\mathrm{SO}_{3}$. Previous studies displayed that adhesion between rubber parts and the cement paste seems to be substantial for the product properties [21].
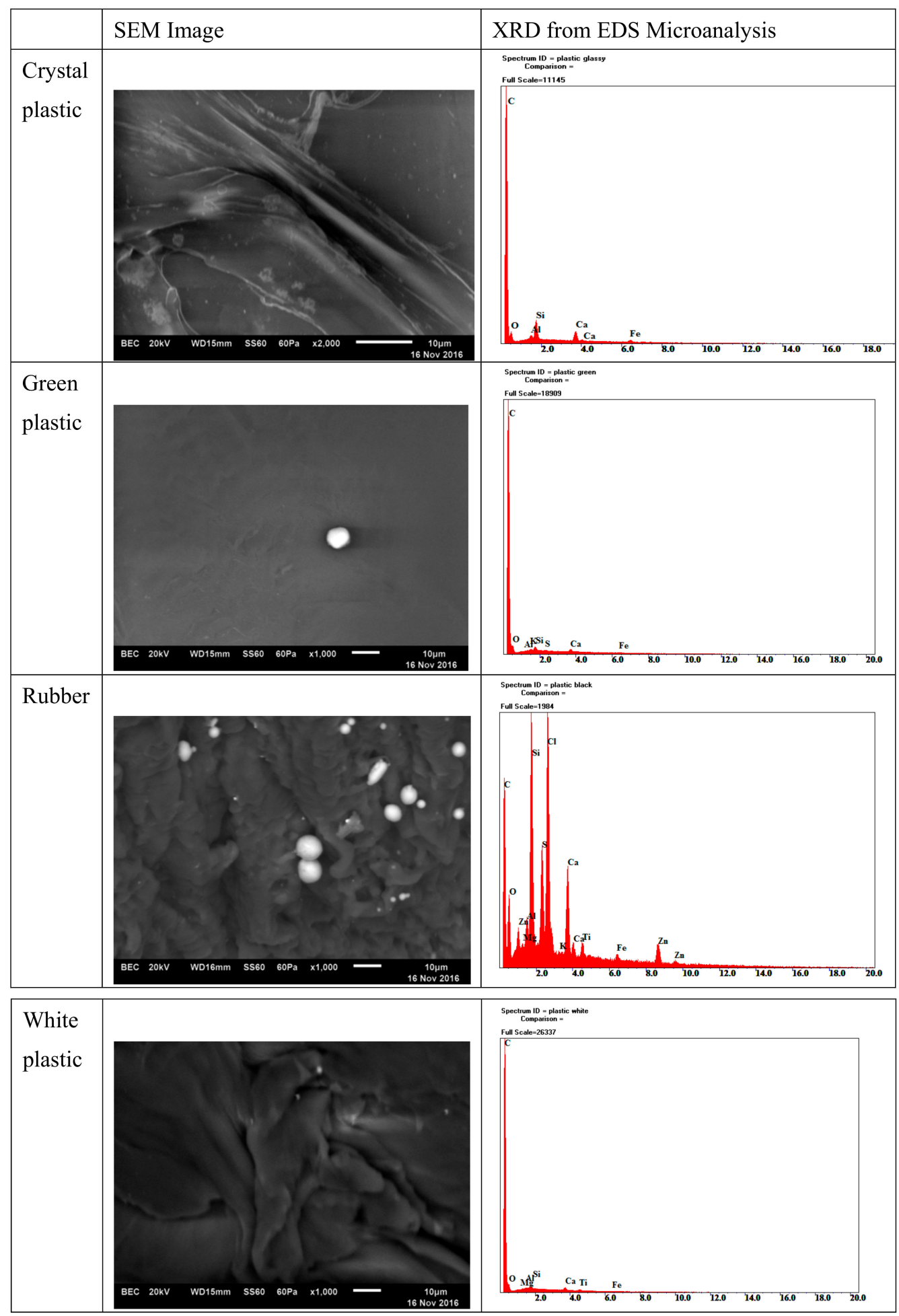

Figure 4. Scanning electron microscopy (SEM) micrographs and energy-dispersive spectroscopy (EDS) microanalysis of materials in expired/waste plastic syringes. 


\subsection{Mixture Proportion}

The binder content for this study was $500 \mathrm{~kg} / \mathrm{m}^{3}$ with a constant water-to-cement ratio of 0.36 . In this experimental study, different series of flowable concrete mixtures incorporating expired plastic syringe particles as a replacement for aggregates were designed. Replacement levels for waste materials were $10 \%-50 \%$ of the fine aggregate weight. The mixture proportions of the flowable concrete with recycled aggregates are presented in Table 3. The mix ID consists of two parts: The number is the replacement percentage and $R$ is the sign of replacement. For example, $20 R$ denotes the mixture with the recycled aggregate replacement of $20 \%$ of the weight of the sand.

Table 3. Mix proportion of flowable concrete using natural and recycled aggregates $\left(\mathrm{kg} / \mathrm{m}^{3}\right)$.

\begin{tabular}{ccccccc}
\hline Name & Cement & Water & CA & FA & SP & RA \\
\hline Control & 500 & 180 & 486 & 1139 & 1.2 & 0 \\
10R & 500 & 180 & 486 & 1025 & 1.2 & 114 \\
20R & 500 & 180 & 486 & 911.2 & 1.3 & 227.8 \\
30R & 500 & 180 & 486 & 797.3 & 1.2 & 341.7 \\
40R & 500 & 180 & 486 & 683.4 & 1.2 & 455.6 \\
50R & 500 & 180 & 486 & 569.5 & 1 & 569.5 \\
\hline
\end{tabular}

SP: Superplasticizer, RA: Recycled aggregate, CA: Natural coarse aggregate, and FA: Natural fine aggregate.

ASTM C 192 [22] allows aggregates to be dried to the saturated-surface-dry (SSD) condition instead of oven-dried. In this study, towels were used to dry the surface moisture from aggregates to add them into the mix in the SSD condition. The dosage of HRWRA is presented with respect to the cementitious material content (by weight) in Table 3. In addition, Figure 5 displays the procedure of the mixing used to prepare the flowable concrete mixes. Natural and recycled aggregates were mixed before batching the concrete mixture.

\begin{tabular}{|c|c|c|c|c|c|c|c|c|}
\hline Adding sequences of the constituen & Coarse Aggregate & $\begin{array}{c}1 / 4 \text { Water } \\
+ \\
1 / 2 \text { HRWRA }\end{array}$ & $\begin{array}{c}\text { Cement } \\
+ \\
\text { Sand }\end{array}$ & $1 / 4$ Water & & Rest & $\begin{array}{c}1 / 4 \text { Water } \\
+ \\
1 / 2 \text { HRWRA }\end{array}$ & $1 / 4$ Water \\
\hline Mixer operating speed (rpm) & 60 & 60 & 120 & 120 & & 0 & 120 & 120 \\
\hline Mixing duration (s) & & 50 & & & 360 & 540 & 66 & 60 \\
\hline
\end{tabular}

Figure 5. Details of the mixing procedure for flowable concrete with recycled aggregates.

During the first $24 \mathrm{~h}$ after pouring, samples were covered with a wet towel at room temperature. Afterward, samples were placed in a lime-saturated water bath at $23 \pm 2{ }^{\circ} \mathrm{C}$, where they were kept until the test day. On the test day, specimens were removed from the water bath and brought to SSD condition before they were tested.

\subsection{Test Practices}

\subsubsection{Workability Measurements}

The superplasticizer (SP) was adjusted in order to prepare a homogeneous mix with a slump flow diameter of $650 \pm 25 \mathrm{~mm}$, as described in the ASTM C 1611 standard [23]. The slump flow T500 test was carried out to take the measurement of the flowable concrete flowability with no obstructions. The purpose of this test was to measure both the flow speed and flow time [24,25]. The T500 time can present the viscosity of the flowable concrete. After preparing the base plate and clean cone, the cone was filled with no agitation or roding. After 30 seconds, the cone was picked up vertically with no interference with the concrete flow, as shown in Figure 6a. To measure the T500 time, the time is started right after the cone case is in contact with the base plate, and timekeeping is continued until the 
concrete reaches a diameter of $500 \mathrm{~mm}$. The greatest diameter of the flow spread was recorded as the slump flow [26].

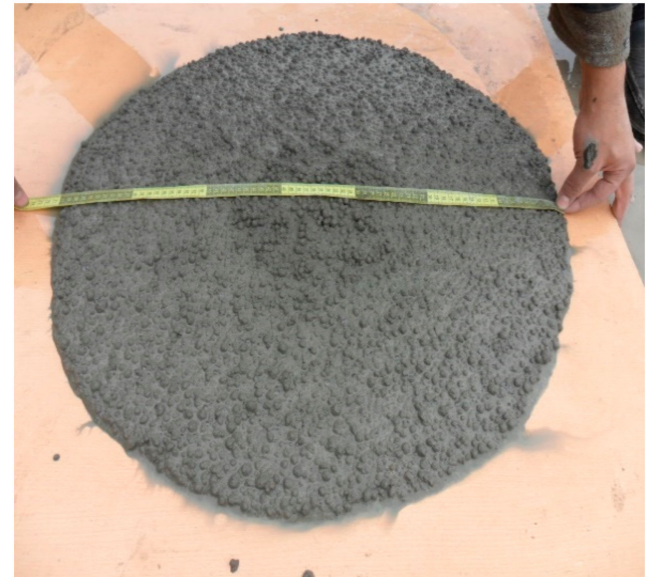

(a) Slump flow test

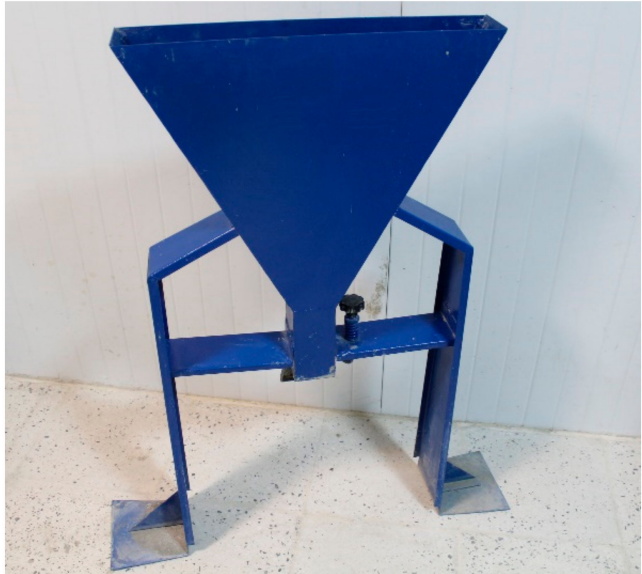

(b) V-funnel test

Figure 6. Workability tests: (a) Slump flow and (b) V-funnel.

The V-funnel was tested based on the BS EN 12350 standard to take a measurement of the flowability through a confined area with no blockage under its own weight. Then, the time that the concrete took to flow through the apparatus $\left(T_{V}\right)$ was recorded. Figure $6 \mathrm{~b}$ presents the method of performing the V-funnel test.

The J-ring test was also used to measure the passing ability of flowable concrete to fill spaces within the formwork. The J-ring setup includes a slump cone in the middle of a cage of rebar, as shown in Figure 7. This test method was conducted based on the EFNARC specifications and ASTM C1621 $[27,28]$. The slump cone is filled with concrete and lifted, and the circular flow of concrete is measured. The J-ring flow test represents the passing ability by measuring the difference in the concrete flow diameters $\left.\left(\mathrm{d}_{2}-\mathrm{d}_{1}\right)\right)$ [29].

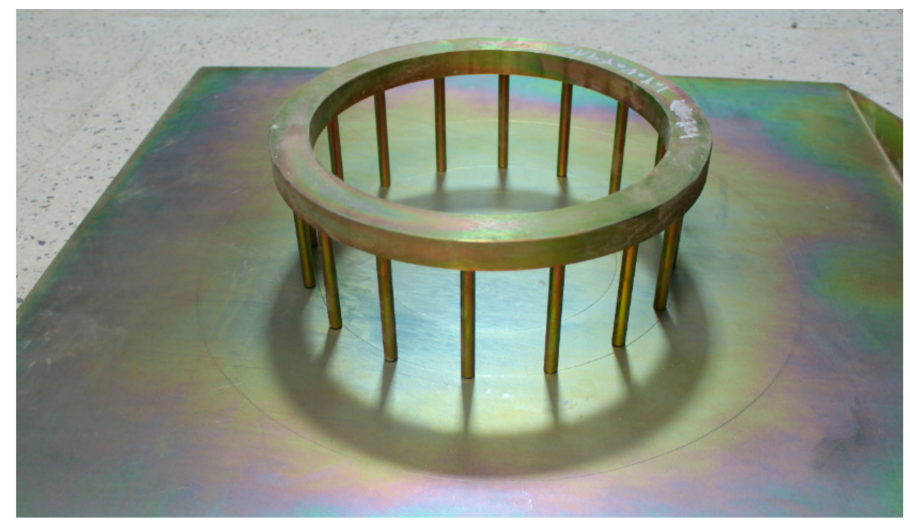

Figure 7. The J-ring test apparatus for testing the passing ability.

In addition, the L-box test was used as a measurement of the workability of flowable concrete in the presence of obstacles by reinforcing bars in accordance with the BS EN 12350 standard. The L-box test setup has an L-shaped rectangular-section box, as shown in Figure 8. The horizontal and vertical parts are separated by a gate, which is removed after the upright part is filled with flowable concrete. The concrete heights at the vertical part $\left(\mathrm{H}_{1}\right)$ and at the end of the horizontal part $\left(\mathrm{H}_{2}\right)$ were recorded. The magnitude of $\mathrm{H}_{2} / \mathrm{H}_{1}$ represents the flowable concrete flowability in the presence of obstacles. 


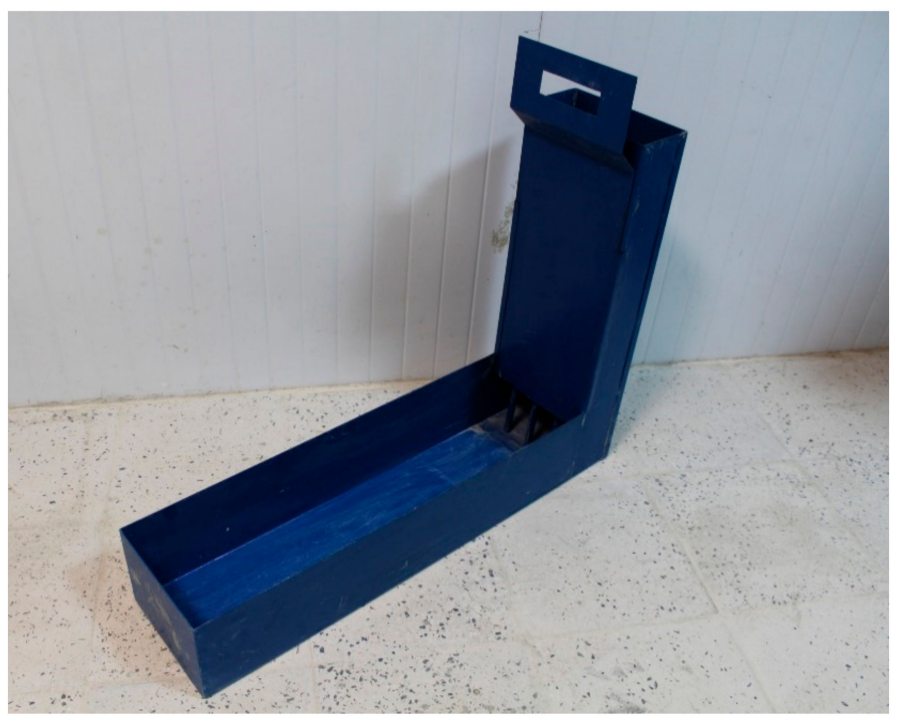

Figure 8. The L-box setup for workability measurement.

The European Federation of National Associations Representing for Concrete (EFNARC) specification defines specific requirements for the flowable concrete material, its composition, and its application. The test procedures that are applied to characterize the properties of flowable concrete have upper and lower limits, as shown in Table 4 . The reason is that all flowability limits should be evaluated to fulfill all requirements.

Table 4. Flowable concrete property requirements according to the European Federation of National Associations Representing for Concrete (EFNARC) [27].

\begin{tabular}{ccccc}
\hline Test Method & Unit & Property & Minimum Range & Maximum Range \\
\hline Slump flow & $\mathrm{mm}$ & Filling ability & 650 & 850 \\
T500 slump flow & $\mathrm{s}$ & Filling ability & 2 & 5 \\
J-ring & $\mathrm{mm}$ & Passing ability & 550 & 750 \\
V-funnel & $\mathrm{s}$ & Filling ability & 6 & 12 \\
L-Box & $\left(\mathrm{H}_{2} / \mathrm{H}_{1}\right)$ & Passing ability & 0.8 & 1.0 \\
\hline
\end{tabular}

\subsubsection{Mechanical Tests}

The compressive strengths of flowable concrete specimens were measured at the ages of 7 , 28, and 91 days based on ASTM C39. The flowable concrete was cast in $100 \times 200 \mathrm{~mm}$ cylinders. Concrete specimens with dimensions of $300 \times 100 \times 100 \mathrm{~mm}$ were cast for flexural strength tests (using a beam with three-point loading) based on the committee C-9 of ASTM C78 [30]. Finally, cylinders with a diameter and height of 100 and $200 \mathrm{~mm}$, respectively, were cast for splitting-tensile tests based on the ASTM C496 [31].

\section{Experimental Results}

\subsection{Fresh Properties}

Figure 9 illustrates the required HRWRA dosage to reach the slump flow target, $650 \pm 25 \mathrm{~mm}$, in each mix. However, the horizontal free flow was changed for flowable concrete mixtures with recycled aggregates. The incorporation of $50 \%$ of recycled aggregate caused the highest demand for HRWRA. There was a greater water absorption by using more waste plastic aggregate. For flowable concrete specimens with $30 \%$ or more plastic content, the water absorption percentage was significantly greater than those of other specimens with no waste materials. Therefore, samples with greater replacement percentages tended to absorb more water on their surfaces and consequently increased 
the water demand of the mixtures. Therefore, the lubricant effect of water decreased and the cohesion of flowable concrete mixes increased, which required a higher level of HRWRA to yield the anticipated slump flow. The average slump flows for $10 \%-20 \%$ recycled aggregate replacements were equal to or greater than that of the control sample. This shows the advantages of using recycled aggregate to improve the workability of flowable concrete by only adding up to $20 \%$ waste materials. However, $30 \%-50 \%$ replacement decreased the slump flow in comparison with that of the control sample. Al-Hadithi and Hilal reported that slump flow diameters ranging from 650 to $780 \mathrm{~mm}$ were obtained for the Self Compacting Concrete (SCC) with plastic waste replacement [32].

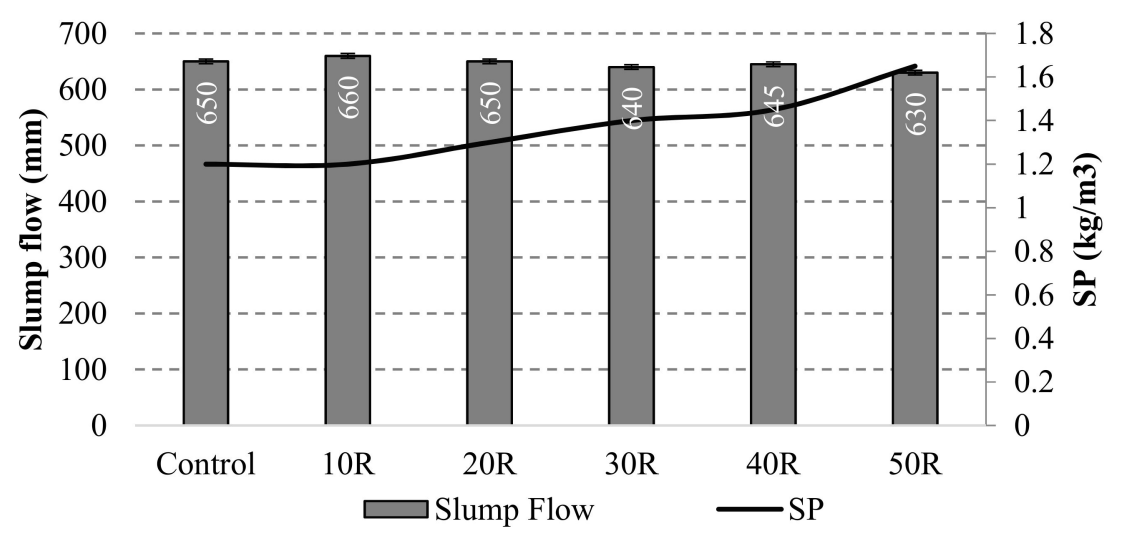

Figure 9. The SP dosage of flowable concrete mixtures to achieve target slump flow.

For all the mixes, although the HRWRA percentage increased with an increased amount of waste aggregate to maintain an acceptable slump, a reduction in the slump flow was seen with increasing waste material content. In addition, the time that the concrete took to achieve the slump flow of $500 \mathrm{~mm}$ was measured (T500). Figure 10 shows that the T500 increased from 2.02 seconds for the control flowable concrete to $2.12,2.26,2.15,2.73$, and 3.34 for flowable concrete with $10 \%-50 \%$ replacements. Although the plastic waste aggregate did not change the slump flow excessively, the homogeneity of the concrete decreased. The comparison between the T500 and V-funnel flow times of the control sample and flowable concrete at different replacement ratios confirmed that adding waste aggregate significantly increased the flow time.

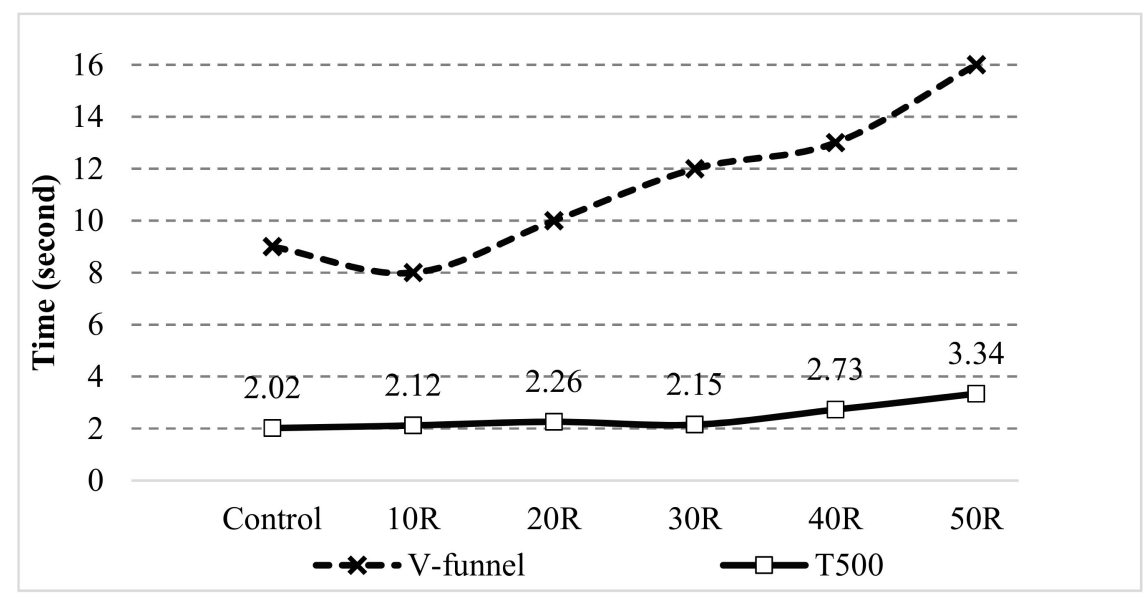

Figure 10. Results of the T500 and V-funnel tests.

The viscosity of flowable concrete was measured by the V-funnel test. Based on the specifications, a longer V-funnel flow time indicates a flowable concrete with greater viscosity. Moreover, those mixtures with shorter V-funnel flow times (i.e., low viscosities) are prone to having segregation [33]. As shown in Figure 10 with a dashed line, using waste aggregates increased the 
V-funnel flow time of flowable concrete; thus, the viscosity of SCC would be increased. The minimum value for the V-funnel was 8 seconds, which corresponded with a $10 \%$ aggregate replacement. Therefore, all of the flowable concrete mixtures were greater than the minimum EFNARC requirement (i.e., 6 seconds). However, using waste aggregates for more than 30\% kept the V-funnel values greater than 12 seconds, which indicated an inappropriate flowability and a viscosity too high for being flowable. Al-Hadithi and Hilal found that the addition of waste plastic increases both T500 slump flow and V-funnel flow times [32].

Figure 11 shows the results of the L-box test. In this test, the L-box values of the mixes, indicating the flowabilities of the mixes, ranged between 0.8 and 1 . The mixes with the lower waste aggregate replacement ratios had higher L-box ratio than those with the higher replacement ratios, indicating higher flowability and workability of the mixtures. Addition of waste aggregate at a 30\%-50\% replacement level decreased the L-box ratio in comparison to that of the control specimen. According to Albano et al., having a higher absorption capacity in mixtures with plastic aggregates can influence the porosity [34]. This behavior can cause an increase in viscosity, as is evident from the reduced L-box ratio magnitudes. The L-box ratio of the mix 10R was greater than those of other mixtures, which indicates that $10 \%$ replacement of waste aggregate was more successful in improving workability in comparison with other replacements. Al-Hadithi and Hilal also reported the same trend in L-box testing [32].

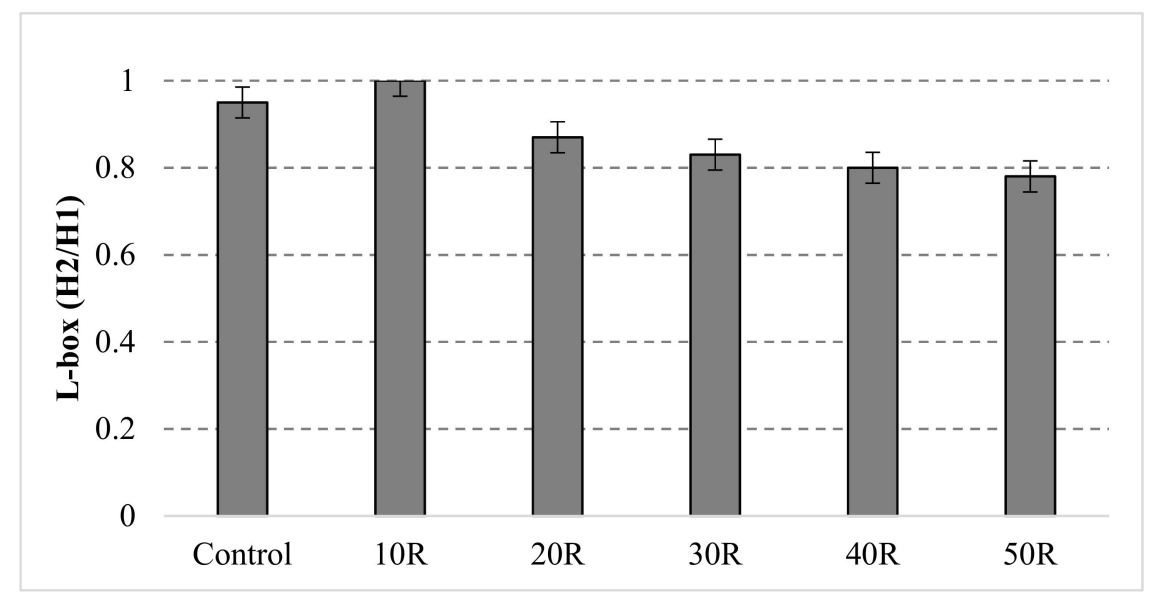

Figure 11. The L-box test results.

The results of the J-ring test also confirmed the results obtained by the L-box, V-funnel, and slump flow tests (see Figure 12). The maximum reduction of mixtures in slump flow in the J-ring test was not higher than $50 \mathrm{~mm}$, except with 50R. Brameshuber and Uebachs [35] reported that a flowable concrete mixture with an acceptable passing ability should have a blocking index (difference between J-ring flow and slump flow) of less than $50 \mathrm{~mm}$ to not see any blockage. Figure 12 demonstrates the influences of recycled aggregate on the J-ring flow results; i.e., the passing ability was decreased for $20 \%-50 \%$ replacements as the J-ring flow decreased. On the contrary, the J-ring flow was improved at the $10 \%$ waste aggregate replacement level, which shows a greater passing ability compared to that of the control sample. The higher percentage of waste materials made the concrete less workable and increased the potential of blocking. Due to the angularity and rough surface texture of the waste aggregate, the passing ability of flowable concrete was decreased by its friction. Safiuddin et al. reported the same behavior when using construction waste aggregates [36]. 


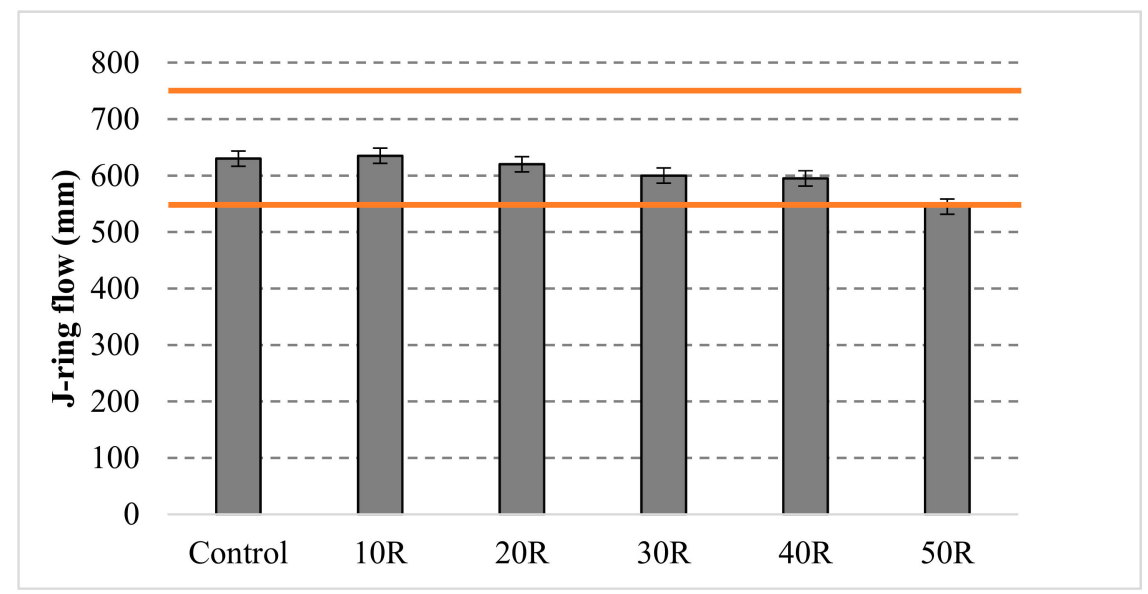

Figure 12. Results of the recycled aggregate on the J-ring flow of concrete.

In order to verify the utility and efficacy of using waste plastic materials, the correlations between different rheological test measurements were calculated by employing the Pearson correlation method, as shown in Table 5 . The correlation coefficient is a number between -1 and +1 . This number can specify how strongly two factors are correlated to each other. Coefficients of -1 and +1 designate great negative and positive correlations, respectively [37]. In this study, an absolute value of a correlation coefficient of greater than 0.8 was considered as a robust correlation. In addition, a correlation coefficient of less than 0.5 was considered as a weak correlation.

Table 5. Pearson correlation numbers of fresh properties.

\begin{tabular}{cccccc}
\hline & Slump Flow & J-Ring & V-funnel & T500 & L-Box \\
\hline Slump Flow & 1 & - & - & - & - \\
J-Ring & 0.935 & 1 & - & - & - \\
V-funnel & -0.942 & -0.982 & 1 & - & - \\
T500 & -0.765 & -0.931 & 0.906 & 1 & - \\
L-Box & 0.8761 & 0.848 & -0.923 & -0.745 & 1 \\
\hline
\end{tabular}

The correlation coefficients between the slump flow, J-ring, L-box, and V-funnel were greater than 0.8 , which shows a strong correlation. However, the T500 test was weakly correlated with other rheological factors. These relationships between the fresh properties were considered as a strong correlation. The effects of using the waste aggregate in flowable concrete by different levels of replacement were identical. In other words, the rheological properties (stability, mobility, and compactability) were improved in the same manner.

\subsection{Mechanical Tests}

The compressive strengths of samples were measured at the ages of 7,28 , and 91 days. As can be seen in Figure 13, at the age of 7 days, samples containing recycled aggregates resulted in lower compressive strength values than that of the control sample. However, at the age of 28 days, using waste aggregates increased the compressive strengths of the samples beyond those of the control mix, except for the $30 \%-50 \%$ replacement percentages. Safi et al. reported that the compressive strength of self-compacting mortars decreased with the increase in plastic waste content at all curing times [38]. At 30\% and 50\% substitution of waste, the percentages of reduction of compressive strength were $15 \%$ and $33 \%$, respectively. Other authors found that, compared to control mixes, up to $72 \%$ reductions in compressive strength were observed for concrete with $20 \%$ replacement $[39,40]$. 


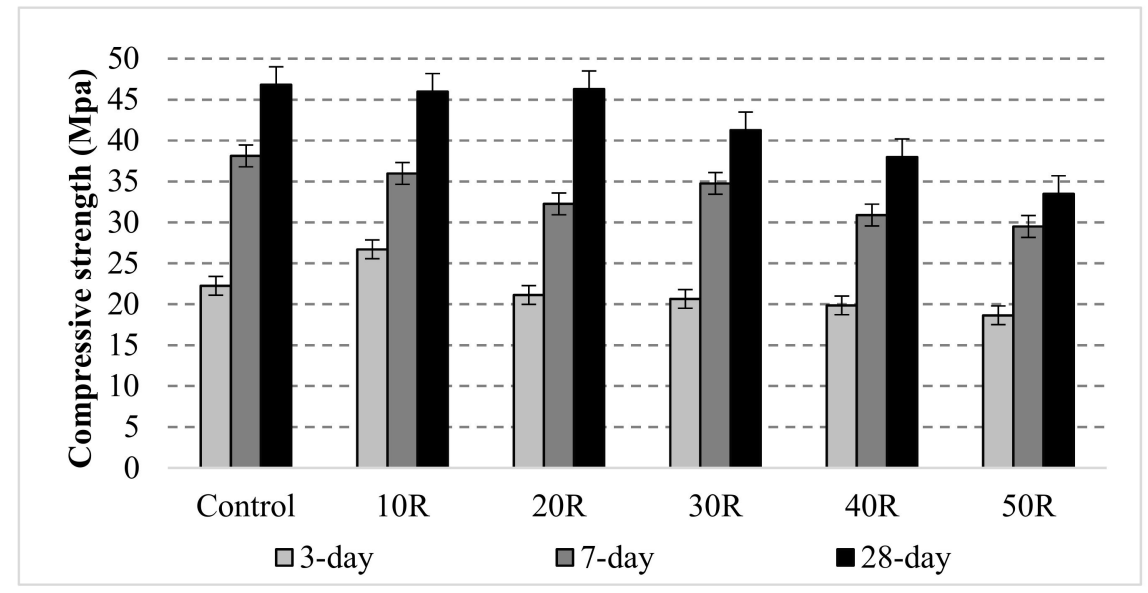

Figure 13. Results of the compressive strength test.

The same trend was seen in the tensile test. As shown in Figure 14, using waste materials as aggregates reduced the splitting-tensile strength of SCC excessively. By using waste products instead of natural aggregates, in comparison with the control sample, the splitting-tensile strengths of samples decreased by $22.3 \%$ by adding $50 \%$ waste. In addition, Figure 15 shows that the average value for the flexural strength test of the control samples was higher than for other samples except 40R after 7 days. However, after 28 days, for flexural strength, there was a great improvement in $20 \%-50 \%$ replacement percentages, as shown in Figure 15. The highest increase was in the SCC samples by adding $40 \%$ waste materials, as the flexural strength increased by $25.8 \%$. Adding $10 \%$ waste materials did not change the flexural strength and decreased it insignificantly. The flexural strength decreased by $35 \%$ by adding $10 \%$ waste products. Other authors reported that the flexural tensile strength decreases with the increase in plastic waste content. Authors found that this is due to the low resistance of the waste [41].

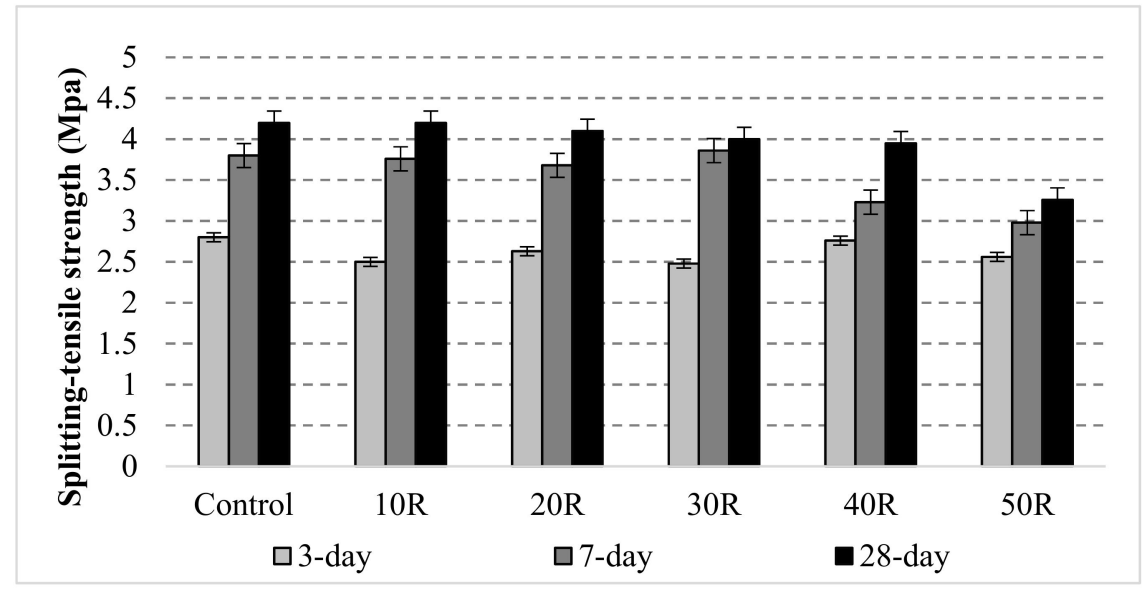

Figure 14. Results of the splitting-tensile strength test. 


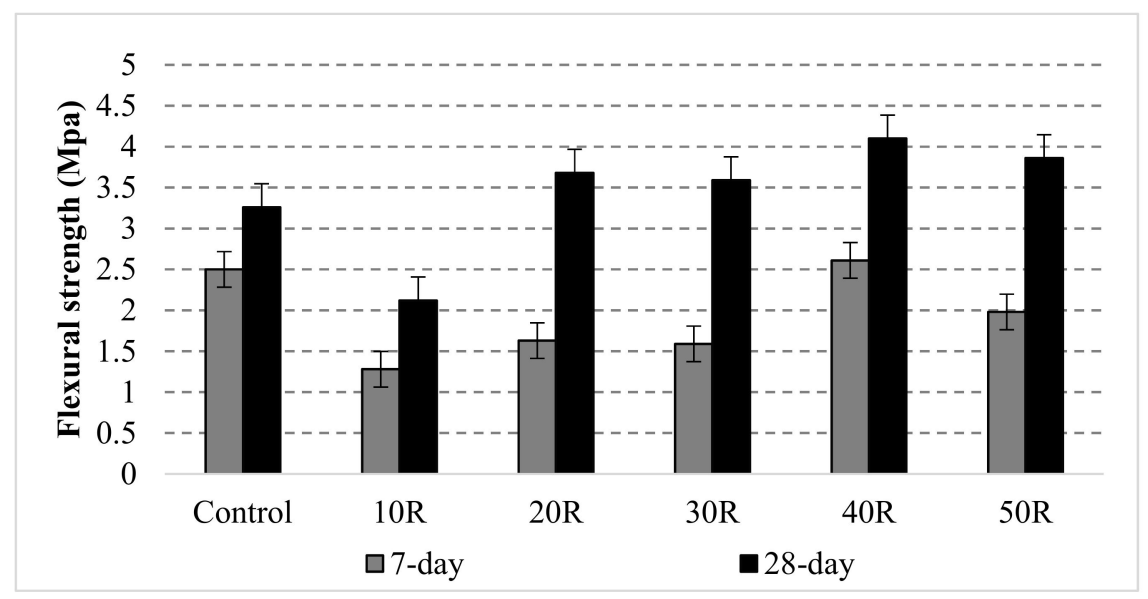

Figure 15. Results of the flexural strength test.

The analysis of variance (ANOVA) is shown in Table 6, which indicates whether the strength differences between samples containing waste replacement and the control sample are significant. As this evaluation was done within the samples in one group, it is called an omnibus test. Based on a defined level of 0.05 , when the significance factor with waste materials is less than or equal to 0.05 , there is a significant difference between this and the strength of the control sample. Otherwise, samples with significance factors of higher than 0.05 have an insignificant difference with the control sample $[42,43]$. When adding waste materials, the compressive strengths and splitting-tensile strengths of flowable concrete samples were decreased, but the magnitudes of strength did not change noticeably at small replacement levels. Table 6 shows that the percentage reduction of 50R compared to the control sample was significant for both compressive and splitting-tensile strengths. Based on statistical analysis, all significance factors are larger than 0.05 for replacing waste materials up to $40 \%$. This indicates that almost all compressive and splitting-tensile strength values were in the same range. Based on ANOVA, adding $10 \%$ waste materials decreased the flexural strength significantly compared to that of the control sample. While using waste materials to replace more than $10 \%$ of the fine aggregates had a slight impact on the flexural strength compared to that of control sample, no notable changes were observed in improving the flexural strength at 28 days.

Table 6. Effects of waste materials on the compressive, splitting-tensile, and flexural strengths of flowable concrete samples after 28 days.

\begin{tabular}{cccccccc}
\hline \multirow{2}{*}{$\begin{array}{c}\text { Mixture } \\
\text { ID }\end{array}$} & $\begin{array}{c}\text { Waste Replacement } \\
\mathbf{( \% )}\end{array}$ & \multicolumn{2}{c}{ Compressive Strength } & \multicolumn{2}{c}{$\begin{array}{c}\text { Splitting-Tensile } \\
\text { Strength }\end{array}$} & \multicolumn{2}{c}{ Flexural Strength } \\
\cline { 3 - 8 } & & Std Dev. & Sig. ${ }^{*}$ & Std Dev. & Sig. & Std Dev. & Sig. \\
\hline Control & 0 & 1.19 & - & 0.56 & - & 0.38 & - \\
\hline $\mathbf{1 0 R}$ & 10 & 0.92 & 1.000 & 0.42 & 1.000 & 0.26 & 0.013 \\
\hline $\mathbf{2 0 R}$ & 20 & 1.20 & 1.000 & 0.26 & 1.000 & 0.14 & 1.000 \\
\hline $\mathbf{3 0 R}$ & 30 & 1.12 & 0.292 & 0.49 & 0.968 & 0.17 & 1.000 \\
\hline $\mathbf{4 0 R}$ & 40 & 0.78 & 0.081 & 0.18 & 0.477 & 0.10 & 0.877 \\
\hline $\mathbf{5 0 R}$ & 50 & 1.51 & 0.002 & 0.41 & 0.032 & 0.08 & 0.995 \\
\hline
\end{tabular}

\section{Limitations and Future Directions}

The legal requirements for different management methods of plastic medical waste along with additional recommended controls and explanations are considered as the key limitations for efficient management of these kinds of wastes. 
The lack of strategic planning among the responsible organizations is a big issue, and there is minimal level of awareness among some hospital staff regarding the risks to the environment resulting from inappropriate management of unused plastic medical waste.

The future avenues for efficient waste management at healthcare facilities would include the better education of healthcare workers and standardized sorting of medical waste streams; hence, further research is required given the trend in increased medical waste production with increasing global GDP.

\section{Role towards Sustainability}

The main role of this research with respect to sustainability is to introduce a more sustainable method of the usage of expired/unused plastic medical waste and puts forward appropriate countermeasures for the acting facilities operation, performance management and other aspects. The environmental and economic burden related to the management of unused plastic medical waste is huge. The data presented in this research pointed out that using expired plastic syringes as fine aggregate in the production of flowable concrete might provide a solution to environmental concerns, in addition to mediating the cost of the waste treatment.

There are a number of moves that governments could make to improve expired plastic syringe treatment and disposal. Firstly, governments should standardize explicit classification of expired plastic/glass syringes and IDUs (injection drug units) and tightly regulate the disposal of each type to prevent their dumping. In addition, governments need to provide healthcare facilities with incentives for reducing sharp production through adequate procurement of staff training and putting into place an accurate database regarding the level of demands that each hospital has in order to avoid over-ordering syringes and other medical devices. Lastly, governments should increase research funding in the area of medical waste reduction and treatment though research grants and industry research partnerships.

\section{Conclusions}

This study explored the properties of flowable concrete made with shredded waste plastic syringes as fine aggregate. The following conclusions can be drawn:

- The amount of water absorption was increased with the incorporation of expired plastic aggregate. Thus, the incorporation of 50\% recycled aggregate caused the highest demand for HRWRA due the greater absorption of water on their surface.

- Using recycled aggregate for up to $20 \%$ can improve the workability of fresh flowable concrete. Therefore, the HRWRA percentage increased with an increased amount of waste aggregate to maintain an acceptable slump.

- Using waste aggregates increased the V-funnel results of flowable concrete mixes; thus, the viscosity of the SCC increased. However, using waste aggregates for more than $30 \%$ made an inappropriate flowability and made the mixes too viscous to be flowable.

- Addition of waste aggregate at a 30\%-50\% replacement level decreased the L-box ratio in comparison to that of the control sample. The $10 \%$ replacement of waste aggregate was more successful in improving workability.

- The results of the J-ring test also confirmed the results obtained by the slump flow, L-box, and V-funnel tests. The correlation coefficients between the slump flow, V-funnel, J-ring, and L-box tests indicate a strong correlation.

- At the age of seven days, the samples containing recycled aggregates showed a lower compressive strength than that of the control sample. However, at the age of 28 days, using waste aggregates increased the compressive strength of the samples (except 30\%-50\% replacements). The same trend was seen in the splitting-tensile and flexural tests. 
Author Contributions: Formal analysis, A.J. and M.G.; Funding acquisition, M.R.; Investigation, M.R.; Methodology, A.J. and M.G.; Writing—original draft, A.J. and M.G.; Writing—review and editing, M.R. All authors have read and agreed to the published version of the manuscript.

Funding: This research received no external funding.

Conflicts of Interest: The authors declare no conflict of interest.

\section{References}

1. Duque-Acevedo, M.; Belmonte-Ureña, L.J.; Cortés-García, F.J.; Camacho-Ferre, F. Agricultural waste: Review of the evolution, approaches and perspectives on alternative uses. Glob. Ecol. Conserv. 2020, 22, e00902. [CrossRef]

2. Elmer, J. The Basel Convention: Effect on the Asian secondary lead industry. J. Power Sources 1996, 59, 1-7. [CrossRef]

3. Akçaözoğlu, S.; Atiş, C.D.; Akçaözoğlu, K. An investigation on the use of shredded waste PET bottles as aggregate in lightweight concrete. Waste Manag. 2010, 30, 285-290. [CrossRef] [PubMed]

4. Mohammed, A.A.; Mohammed, I.I.; Mohammed, S.A. Some properties of concrete with plastic aggregate derived from shredded PVC sheets. Constr. Build. Mater. 2019, 201, 232-245. [CrossRef]

5. Hama, S.M.; Hilal, N.N. Fresh properties of self-compacting concrete with plastic waste as partial replacement of sand. Int. J. Sustain. Built Environ. 2017, 6, 299-308. [CrossRef]

6. Gesoglu, M.; Güneyisi, E.; Hansu, O.; Etli, S.; Alhassan, M. Mechanical and fracture characteristics of self-compacting concretes containing different percentage of plastic waste powder. Constr. Build. Mater. 2017, 140, 562-569. [CrossRef]

7. Sadrmomtazi, A.; Dolati-Milehsara, S.; Lotfi-Omran, O.; Sadeghi-Nik, A. The combined effects of waste Polyethylene Terephthalate (PET) particles and pozzolanic materials on the properties of self-compacting concrete. J. Clean. Prod. 2016, 112, 2363-2373. [CrossRef]

8. Pouranian, M.R.; Notani, M.A.; Tabesh, M.T.; Nazeri, B.; Shishehbor, M. Rheological and environmental characteristics of crumb rubber asphalt binders containing non-foaming warm mix asphalt additives. Constr. Build. Mater. 2020, 238, 117707. [CrossRef]

9. Gonzalez-Sanchez, J.F; Fernandez-Alvarez, J.M.; Alvarez, J.I.; Navarro-Blasco, I.Í. Solidification/Stabilization of hazardous wastes from the mine La Prieta in Hidalgo del Parral, Chihuahua, México. Available online: https: //dadun.unav.edu/bitstream/10171/43879/1/2017-04-06-X\%20JICES-Poster-Fidel.pdf (accessed on 12 January 2020).

10. Thomas, B.S.; Gupta, R.C. a comprehensive review on the applications of waste tire rubber in cement concrete. Renew. Sustain. Energy Rev. 2016, 54, 1323-1333. [CrossRef]

11. Gupta, T.; Chaudhary, S.; Sharma, R.K. Assessment of mechanical and durability properties of concrete containing waste rubber tire as fine aggregate. Constr. Build. Mater. 2014, 73, 562-574. [CrossRef]

12. Asokan, P.; Osmani, M.; Price, A. Assessing the recycling potential of glass fibre reinforced plastic waste in concrete and cement composites. J. Clean. Prod. 2009, 17, 821-829. [CrossRef]

13. Boadella, I.L.; Gayarre, F.L.; González, J.S.; Gómez-Soberón, J.M.; Pérez, C.L.-C.; López, M.S.; De Brito, J. The influence of granite cutting waste on the properties of ultra-high performance concrete. Materials 2019, 12, 634. [CrossRef] [PubMed]

14. Kim, J.-H.J.; Park, C.-G.; Lee, S.-W.; Lee, S.-W.; Won, J.-P. Effects of the geometry of recycled PET fiber reinforcement on shrinkage cracking of cement-based composites. Compos. Part B Eng. 2008, 39, 442-450. [CrossRef]

15. Kou, S.; Lee, G.; Poon, C.; Lai, W. Properties of lightweight aggregate concrete prepared with PVC granules derived from scraped PVC pipes. Waste Manag. 2009, 29, 621-628. [CrossRef] [PubMed]

16. Gadea, J.; Rodríguez, A.; Campos, P.; Garabito, J.; Calderón, V. Lightweight mortar made with recycled polyurethane foam. Cem. Concr. Compos. 2010, 32, 672-677. [CrossRef]

17. Lei, Z.; Bahia, H.; Yi-qiu, T.; Ling, C. Effects of refined waste and bio-based oil modifiers on rheological properties of asphalt binders. Constr. Build. Mater. 2017, 148, 504-511. [CrossRef]

18. Khayat, K.H.; Meng, W. Design and Performance of Stay-in-Place UHPC Prefabricated Panels for Infrastructure Construction; Center for Transportation; Missouri University of Science and Technology: Rolla, MO, USA, 2014.

19. Labuschagne, J.-C. Formwork Pressures by Self-Compacting Concrete: a Practical Perspective; Stellenbosch University: Stellenbosch, South Africa, 2018. 
20. Salek, S.; Samali, B.; Murphy, T.; Wuhrer, R.; Adam, G. Comparative study between microstructure of a novel durable concrete and normal concrete subjected to harsh environments. In Proceedings of the 9th International Conference on Fracture Mechanics of Concrete and Concrete Structures, San Francisco, CA, USA, 29 May-1 June 2016.

21. Karakurt, C. Microstructure properties of waste tire rubber composites: An overview. J. Mater. Cycles Waste Manag. 2015, 17, 422-433. [CrossRef]

22. American Society for Testing and Materials. C192 Standard Practice for Making and Curing Concrete Test Specimens in the Laboratory; ASTM International: West Conshohocken, PA, USA, 2002.

23. American Society for Testing and Materials. C1611 Standard Test Method for Slump Flow of Self-Consolidating Concrete; ASTM International: West Conshohocken, PA, USA, 2009.

24. Ardalan, R.B.; Joshaghani, A.; Hooton, R.D. Workability retention and compressive strength of self-compacting concrete incorporating pumice powder and silica fume. Constr. Build. Mater. 2017, 134, 116-122. [CrossRef]

25. Joshaghani, A. Workability Retention and Mechanical Properties of Self-Compacting Concrete (SCC) with Sugar Cane Bagasse Ash (SCBA) and Rice Husk Ash (RHA); Nova Science Publishers: New York, NY, USA, 2017; pp. 233-258.

26. Ardalan, R.B.; Emamzadeh, Z.N.; Rasekh, H.; Joshaghani, A.; Samali, B. Physical and mechanical properties of polymer modified self-compacting concrete (SCC) using natural and recycled aggregates. J. Sustain. Cem. Based Mater. 2019. [CrossRef]

27. Efnarc, S. Guidelines for Self-Compacting Concrete; Efnarc Association House: Farnham, UK, 2002; pp. 1-32. Available online: www.efnarc.org.

28. Russell, H.G. ASTM Test Methods for Self-Consolidating Concrete. HPC Bridge Views 2008, 50, 1-11.

29. Askarian, M.; Fakhretaha Aval, S.; Joshaghani, A. a comprehensive experimental study on the performance of pumice powder in self-compacting concrete (SCC). J. Sustain. Cem. Based Mater. 2018, 7, 340-356. [CrossRef]

30. ASTM International. Standard Test Method for Flexural Strength of Concrete (Using Simple Beam with Third-Point Loading); Committee C09 on Concrete and Concrete Aggregates: West Conshohocken, PA, USA, 2016.

31. Norma, A. C496/C496M-11. In Standard Test Method for Splitting Tensile Strength of Cylindrical Concrete Specimens; ASTM International: West Conshohocken, PA, USA, 2004; pp. 469-490.

32. Al-Hadithi, A.I.; Hilal, N.N. The possibility of enhancing some properties of self-compacting concrete by adding waste plastic fibers. J. Build. Eng. 2016, 8, 20-28. [CrossRef]

33. Karein, S.M.M.; Joshaghani, A.; Ramezanianpour, A.; Isapour, S.; Karakouzian, M. Effects of the mechanical milling method on transport properties of self-compacting concrete containing perlite powder as a supplementary cementitious material. Constr. Build. Mater. 2018, 172, 677-684. [CrossRef]

34. Albano, C.; Camacho, N.; Hernandez, M.; Matheus, A.; Gutierrez, A. Influence of content and particle size of waste pet bottles on concrete behavior at different w/c ratios. Waste Manag. 2009, 29, 2707-2716. [CrossRef]

35. Brameshuber, W.; Uebachs, S. Practical experience with the application of self-compacting concrete in Germany. In Proceedings of the 2nd International Symposium on Self-Compacting Concrete, Tokyo, Japan, 3-5 October 2001; pp. 687-696.

36. Safiuddin, M.; Salam, M.; Jumaat, M. Effects of recycled concrete aggregate on the fresh properties of self-consolidating concrete. Arch. Civ. Mech. Eng. 2011, 11, 1023-1041. [CrossRef]

37. Joshaghani, A.; Bhardwaj, R.; Zollinger, D.G.; Mukhopadhyay, A.K. Investigating the Effects of Curing Quality on Key Concrete Pavement Surface Properties. Transp. Res. Rec. 2019. [CrossRef]

38. Safi, B.; Saidi, M.; Aboutaleb, D.; Maallem, M. The use of plastic waste as fine aggregate in the self-compacting mortars: Effect on physical and mechanical properties. Constr. Build. Mater. 2013, 43, 436-442. [CrossRef]

39. Ferreira, L.; de Brito, J.; Saikia, N. Influence of curing conditions on the mechanical performance of concrete containing recycled plastic aggregate. Constr. Build. Mater. 2012, 36, 196-204. [CrossRef]

40. Saikia, N.; De Brito, J. Use of plastic waste as aggregate in cement mortar and concrete preparation: a review. Constr. Build. Mater. 2012, 34, 385-401. [CrossRef]

41. Rai, B.; Rushad, S.T.; Kr, B.; Duggal, S.K. Study of waste plastic mix concrete with plasticizer. ISRN Civ. Eng. 2012, 2012, 1-5. [CrossRef] 
42. Tabatabaeian, M.; Khaloo, A.; Joshaghani, A.; Hajibandeh, E. Experimental investigation on effects of hybrid fibers on rheological, mechanical, and durability properties of high-strength SCC. Constr. Build. Mater. 2017, 147, 497-509. [CrossRef]

43. Jafari, K.; Tabatabaeian, M.; Joshaghani, A.; Ozbakkaloglu, T. Optimizing the mixture design of polymer concrete: An experimental investigation. Constr. Build. Mater. 2018, 167, 185-196. [CrossRef]

(C) 2020 by the authors. Licensee MDPI, Basel, Switzerland. This article is an open access article distributed under the terms and conditions of the Creative Commons Attribution (CC BY) license (http://creativecommons.org/licenses/by/4.0/). 